\title{
Tracking neuronal dynamics during seizures
}

\author{
Ghanim Ullah ${ }^{1 *}$, Steven J Schiff ${ }^{1,2}$ \\ From Nineteenth Annual Computational Neuroscience Meeting: CNS*2010 \\ San Antonio, TX, USA. 24-30 July 2010
}

We demonstrate that a meaningful estimation of the neuronal network dynamics from single measured variable is now possible by incorporating biophysical neuronal models into a model-based control framework. Specifically, we assimilate noisy membrane potential (V) measurements from individual hippocampal neurons to reconstruct the dynamics of networks of these cells, their extracellular microenvironment, and the activities of different neuronal types during seizures.

We used two-compartmental models for the pyramidal cells (PCs) and interneurons (INs): a cellular compartment and the surrounding extracellular microenvironment. The membrane potentials of both cells were modeled by
Hodgkin-Huxley equations containing sodium, potassium, calcium-gated potassium, and leak currents. The current equations were augmented with dynamic variables representing the intra- and extracellular ion concentrations $\left(\mathrm{K}^{+}\right.$, $\mathrm{Na}^{+}$, and $\mathrm{Ca}^{2+}$ ). To estimate and track the dynamics of the neuronal networks, we applied a nonlinear ensemble version of the Kalman filter, the Unscented Kalman Filter (UKF) [1]. Details of the model and UKF implementation can be found in $[2,3]$.

In Fig. 1 we show an example where we use $\mathrm{V}$ measurements to estimate the rest of the dynamics of CA1 PC. Fig. 1A shows an intracellular recording from a PC during seizures, and plot the estimated $[\mathrm{K}]_{\mathrm{o}}$ in Fig. 1B.
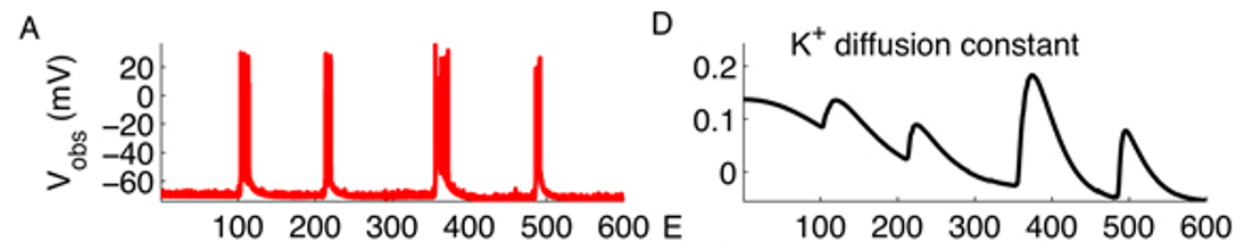

B

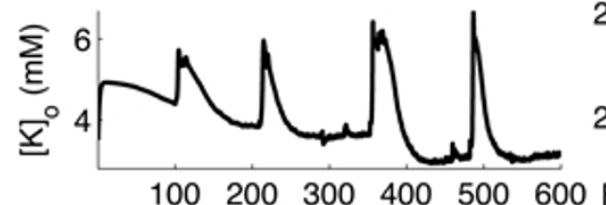

23.76 Glial buffering strength

C
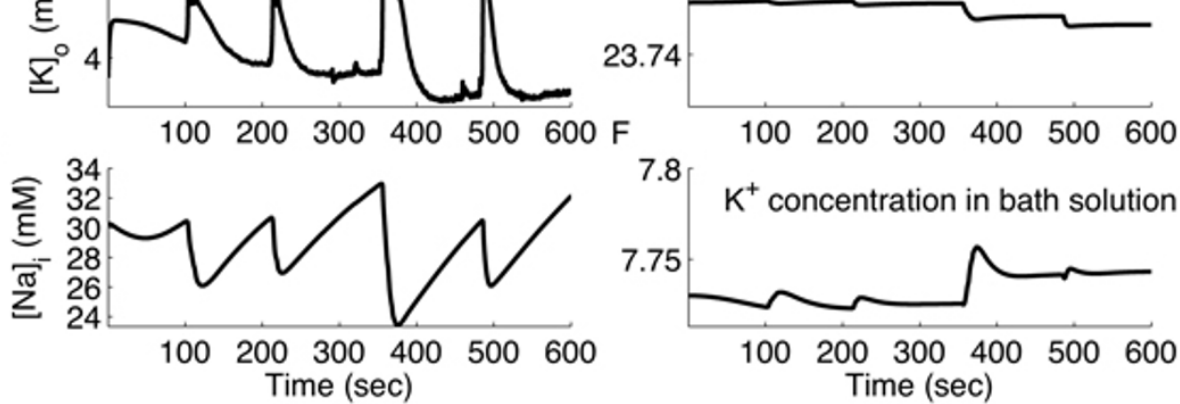

Figure 1 Assimilating spontaneous seizure data by whole cell recording from CA1 hippocampal pyramidal neurons. (A) Measured $V$ (red) from single PC during spontaneous seizures. Estimated (black) $[K]_{0}(B),[N a]_{i}(C), K^{+}$diffusion constant (D), glial buffering strength (E), and $K^{+}$ concentration in bath solution (F).

\footnotetext{
* Correspondence: ghanim@psu.edu

${ }^{1}$ Center for Neural Engineering, Department of Engineering Science and Mechanics, Pennsylvania State University, University Park, PA 16802, USA
} 
As is clear from the figure the $[\mathrm{K}]_{\mathrm{o}}$ oscillates as the cell goes into and out of seizures. The $[\mathrm{K}]_{\mathrm{o}}$ begins to rise as the cell enters seizures and peaks with the maximal firing frequency, followed by decreasing $[\mathrm{K}]_{\mathrm{o}}$ as the firing rate decreases and the seizure terminates. Higher $[\mathrm{K}]_{\mathrm{o}}$ makes the PC more excitable by raising the reversal potential for $\mathrm{K}^{+}$currents. The increased $\mathrm{K}^{+}$reversal potential causes the cell to burst fire spontaneously. Changes in the $[\mathrm{Na}]_{i}$ are closely coupled with the changes of $[\mathrm{K}]_{\mathrm{o}}$ (Fig. 1C). As shown in panels (1D-F) we reconstructed the parameters controlling the microenvironment of the cell. These parameters included the diffusion constant of $\mathrm{K}^{+}$in the extracellular space, $\mathrm{K}^{+}$ buffering strength of glia, and $\mathrm{K}^{+}$concentration in the reservoir of the perfusing solution in vitro (or in the vasculature in vivo) during seizures.

In conclusion, we demonstrated that estimating the neuronal microenvironment and neuronal interactions can be performed by embedding our improving neuronal models within a model-based state estimation framework. This approach can provide a more complete understanding of otherwise incompletely observed neuronal dynamics during normal and pathological brain function.

\section{Author details}

${ }^{1}$ Center for Neural Engineering, Department of Engineering Science and Mechanics, Pennsylvania State University, University Park, PA 16802, USA. ${ }^{2}$ Departments of Neurosurgery and Physics, Pennsylvania State University, University Park, PA 16802, USA.

Published: 20 July 2010

\section{References}

1. Kalman RE: A new approach to linear filtering and prediction problems. Trans ASME J Basic Eng 1960, 82:35-45.

2. Cressman JR Jr, Ullah G, Ziburkus J, Schiff SJ, Barreto E: The influence of sodium and potassium dynamics on excitability, seizures, and the stability of persistent states: I. Single neuron dynamics. J Comput Neurosci 2009, 26:159-170.

3. Ullah G, Schiff SJ: Tracking and control of neuronal Hodgkin-Huxley dynamics. Phys Rev E Stat Nonlin Soft Matter Phys 2009, 79:040901.

4. Ziburkus J, Cressman JR Jr, Barreto E, Schiff SJ: Interneuron and pyramidal cell interplay during in vitro seizure-like events. J Neurophysiol 2006 , 95:3948-3954.

doi:10.1186/1471-2202-11-S1-O9

Cite this article as: Ullah and Schiff: Tracking neuronal dynamics during seizures. BMC Neuroscience 2010 11(Suppl 1):O9.

\section{Submit your next manuscript to BioMed Central} and take full advantage of:

- Convenient online submission

- Thorough peer review

- No space constraints or color figure charges

- Immediate publication on acceptance

- Inclusion in PubMed, CAS, Scopus and Google Scholar

- Research which is freely available for redistribution

Submit your manuscript at www.biomedcentral.com/submit 